\title{
Myocardial adaptations in the failing heart: cause or consequence?
}

\author{
Sabine J. van Dijk · Nazha Hamdani · \\ Ger J. M. Stienen · Jolanda van der Velden
}

Received: 4 December 2008/ Accepted: 7 January 2009/Published online: 14 February 2009

(C) The Author(s) 2009. This article is published with open access at Springerlink.com

\begin{abstract}
Many changes in morphology, biochemical properties and myocyte function occur during development to heart failure. Most changes may be compensatory, yet unable to prevent cardiac dysfunction in the long run. This illustrates that it is important to carefully dissect the disease causing modifications from cardiac adaptation, in order to obtain a better understanding of the pathophysiological processes leading to heart failure.
\end{abstract}

Keywords Heart failure - Myocyte contractility · Protein phosphorylation

\section{Introduction}

Heart failure is a disease with a broad clinical presentation and a complex underlying pathophysiology. A variety of cardiac diseases can damage the heart and trigger the process leading to heart failure (Francis 2001). Although the exact mechanisms involved in the progression towards heart failure are not yet fully understood, the involvement of many mechanical, biochemical and genetic factors has become evident over the recent years.

Structural remodelling of the heart, including hypertrophy, apoptosis and slippage of myocytes and altered extracellular matrix turnover, is frequently observed in heart failure. Remodelling often occurs in response to a primary defect, such as a myocardial infarction or

S. J. van Dijk $(\varangle) \cdot$ N. Hamdani · G. J. M. Stienen ·

J. van der Velden

Laboratory for Physiology, Institute for Cardiovascular

Research, VU University Medical Center, van der

Boechorststraat 7, 1081 BT Amsterdam, The Netherlands

e-mail: s.vandijk@vumc.nl hypertension, and is frequently acknowledged to contribute to ventricular dysfunction (Francis 2001; Radauceanu et al. 2008; Yankey et al. 2008).

Several biochemical factors, e.g. cytokines and neurohormones, have been shown to be associated with heart failure (Mahmoudabady et al. 2008; Ratnasamy et al. 2008; Torre-Amione et al. 1996; van Empel and De Windt 2004). Overexpression of TNF- $\alpha$ contributes to cardiac remodelling by inducing hypertrophy and apoptosis of myocytes. In transgenic mice models this overexpression induces heart failure (Bryant et al. 1998). Activation of the reninangiotensin system worsens the progression of heart failure by promoting water and salt retention and vasoconstriction, thereby raising blood pressure (Ram 2008). Furthermore, angiotensin II is implicated to exert a direct effect on remodelling by stimulating cardiomyocyte hypertrophy and extracellular matrix production (Billet et al. 2008). Sympathetic nervous activity is elevated in heart failure to maintain cardiac output, which is reflected by high levels of catecholamines. Overstimulation of the sympathetic system leads to desensitisation and downregulation of $\beta$-adrenergic receptors in heart failure (Bristow et al. 1993). The natriuretic system influences hemodynamics and variations in this system are associated with increased risk for cardiovascular disease (Lanfear 2008).

Genetic factors involved in heart failure are becoming increasingly clear both in hypertrophic (HCM) and dilated cardiomyopathy (DCM). HCM is characterized by thickening of the septum and left ventricular wall without an underlying cardiac or systemic defect. HCM is a heterogeneous disease with a wide range of clinical presentations. Familial HCM (FHCM) is the most frequent inheritable cardiac disease, caused by mutations in genes encoding for several sarcomeric proteins (Maron 2004). DCM is characterized by an increased left ventricular volume and a 
reduced ejection fraction (systolic failure). Although mutations, some of which located in the sarcomeric proteins, have been found to cause DCM, mostly the cause is unknown. It has been proposed that HCM eventually evolves to DCM, although there is also evidence suggesting dissimilar pathomechanisms for HCM and DCM without a common endpoint.

\section{Myocyte contractility in heart failure}

Cardiac function is largely determined by the contractile properties of the sarcomere. During contraction, the myosin of the thick filament and the actin of the thin filament interact. A rise in intracellular free $\mathrm{Ca}^{2+}$ initiates contraction by binding of $\mathrm{Ca}^{2+}$ to troponin $\mathrm{C}$. As a result, the tropomyosin-troponin complex changes its conformation, thereby unblocking the myosin binding site on actin and allowing crossbridge formation. A number of sarcomeric proteins are involved in the regulation of contraction (reviewed by de Tombe 2003).

Several changes in expression of proteins involved in contraction have been found in heart failure, such as a decreased $\alpha$-myosin heavy chain expression, a shift in titin isoform from the shorter N2B to the longer, more compliant N2BA isoform (McDonald and Herron 2002; Nakao et al. 1997).

\section{Troponin I and myosin binding protein $\mathrm{C}$ phosphorylation in heart failure}

The function of many cardiac sarcomeric proteins is regulated by post translational modifications, in particular phosphorylation (for a recent review, see, Jin et al. 2008). The foremost kinases active in the heart are protein kinase A (PKA), protein kinase $\mathrm{C}$ (PKC) and $\mathrm{Ca}^{2+}$-dependent calmodulin kinase 2 (CamK2). The phosphorylation status of sarcomeric proteins is influenced by phosphatase activity of protein phosphates 1 and $2 \mathrm{~A}$ as well.

PKA is activated upon $\beta$-adrenergic stimulation and is a key player in cardiac adaptation to increased cardiac demand. The main sarcomeric protein targets of PKA dependent phosphorylation are cardiac troponin I (cTnI), myosin binding protein $\mathrm{C}$ (cMyBP-C) and titin. PKC phosphorylates several sites on $\mathrm{cTnI}$, cardiac troponin $\mathrm{T}$ (cTnT) and cMyBP-C. Several studies have reported a downregulation of PKA and an upregulation of PKC in heart failure (LeWinter 2005; Sumandea et al. 2004).

Phosphorylation of cTnI by PKA is associated with reduced $\mathrm{Ca}^{2+}$-sensitivity and increased crossbridge kinetics, enabling fast relaxation and so maintaining adequate diastolic function at elevated cardiac output (Hamdani et al. 2008; LeWinter 2005). Ample evidence suggests a role for PKA dependent activation of $\mathrm{CMyBP}-\mathrm{C}$ in the kinetics of force development. In mice, treatment of skinned ventricular myocardium with PKA accelerated stretch activation, an effect not seen in myocardium from cMyBPC knock out mice (Stelzer et al. 2007). The functional consequences of cMyBP-C phosphorylation by PKC are less well studied (Lim et al. 1985; Xiao et al. 2007).

\section{Altered cTnI and cMyBP-C phosphorylation in human heart failure}

Research on the pathophysiology of inheritable cardiomyopathies is mainly conducted in animal models. Additionally, the functional consequences of FHCM causing mutations are largely studied in vitro, using (parts of) exogenous protein. Human studies in more physiological circumstances are scarce but the delicate regulation of the sarcomere, e.g. by phosphorylation, is currently subject of intense study (El Armouche et al. 2007; Jacques et al. 2008). Phosphorylation of PKA-target proteins $\mathrm{cTnI}$ and cMyBP-C appears to be reduced in myocardium of endstage heart failure patients (Bodor et al. 1997; Messer et al. 2007; van der Velden et al. 2006). Less is known about the phosphorylation of these proteins in FHCM.

Hence, we investigated whether the phosphorylation status of sarcomeric proteins in FHCM differs from that in idiopathic DCM (IDCM) and non-failing donor samples. Sarcomeric proteins were separated on a gradient gel and stained with ProQ Diamond and SYPRO Ruby stain to determine phosphorylation and expression level, respectively, as described previously (Zaremba et al. 2007). In accordance with previous studies, we demonstrated a reduced phosphorylation of cTnI and $\mathrm{cMyBP}-\mathrm{C}$ in IDCM $(n=12)$ compared to non-failing donor samples $(n=10)$ by $87 \pm 3$ and $55 \pm 5 \%$, respectively (Fig. 1). The phosphorylation level of cMyBP-C was lowered in FHCM patients $(n=25)$ compared to donors as well $(0.64 \pm 0.07$ vs. $1.0 \pm 0.04$, respectively, $P<0.05$ in one-way ANOVA followed by post-test Bonferroni analysis; Fig. 1), although not to the extent observed in IDCM samples. Considerable variation in cMyBP-C was observed in the FHCM samples, underlining the heterogeneous character of FHCM. Therefore, we analysed phosphorylation in a more homogenous subgroup of patients with a mutation in $M Y B P C 3$, the gene encoding cMyBP-C. Surprisingly, cMyBP-C phosphorylation was alike in donor and MYBPC3 mutant FHCM samples (data not shown). cTnI phosphorylation was lowered considerably by $86 \pm 4 \%$ in FHCM patients compared to donor, similar to the reduction observed in IDCM patients. 
A. cTnl phosphorylation relative to $\alpha$-actinin

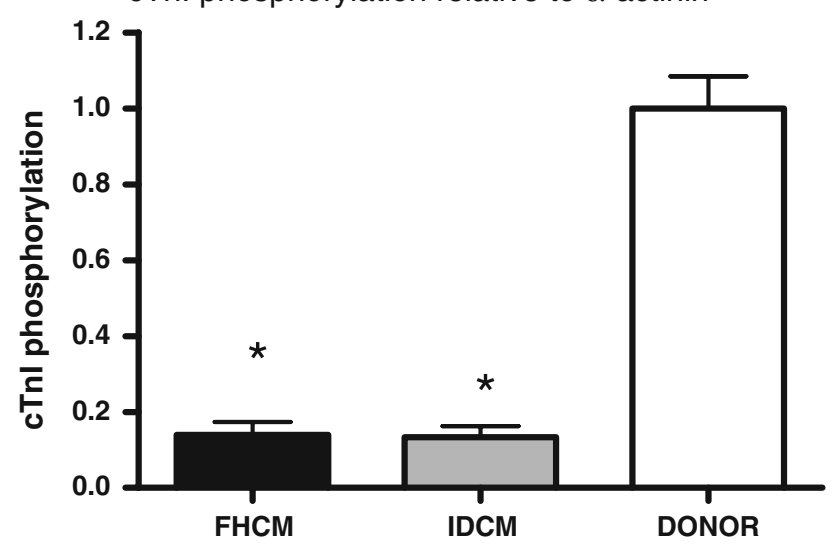

B. CMyBP-C phosphorylation relative to $\mathrm{CMyBP}-\mathrm{C}$

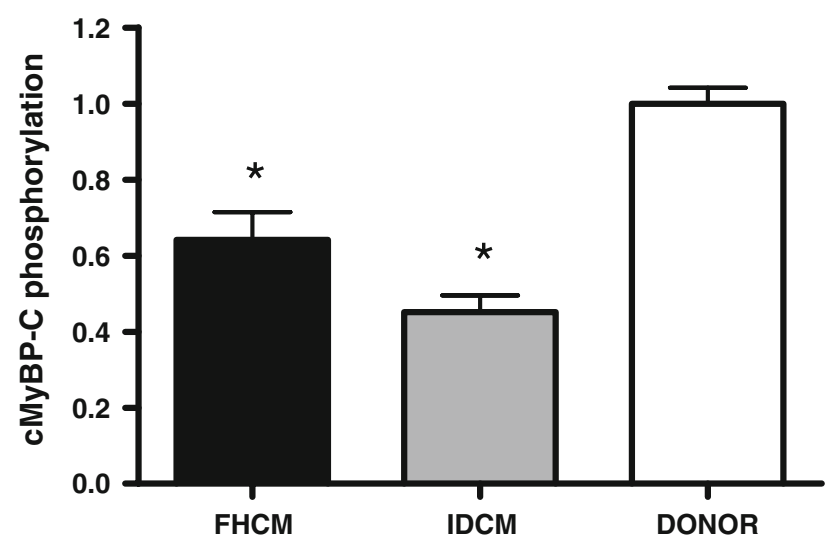

Fig. 1 Phosphorylation status of cTnI and cMyBP-C. a ProQ Diamond staining of SDS-PAGE gels showed that the phosphorylation status of cTnI (relative to the intensity of the SYPRO Ruby stained $\alpha$-actinin band) was lower in IDCM $(n=12)$ and FHCM $(n=25)$ compared to donor $(n=10)$ samples. b The phosphorylation status of cMyBP-C (relative to the intensity of the SYPRO Ruby cMyBP-C band) was lower in IDCM than in donor, but comparable between FHCM and donor samples. All values of IDCM and FHCM are given relative to values found in donor, which were set to 1 . $* P<0.05$ failing versus donor in one-way ANOVA followed by post-test Bonferroni analysis

\section{Conclusions}

Careful investigation of changes in morphology, biochemical profile and genetics of heart failure patients is required to enhance our understanding of the pathophysiology of heart failure and of myocyte function in general. It will be difficult to make a distinction between pathological adaptations and compensatory mechanisms, because a number of changes occur simultaneously. We demonstrated divergent phosphorylation of $\mathrm{cTnI}$ and cMyBP-C in distinct patient groups. Furthermore, the high variability observed even within the FHCM patient group emphasises the wide range of adaptations that occur during heart failure.
Open Access This article is distributed under the terms of the Creative Commons Attribution Noncommercial License which permits any noncommercial use, distribution, and reproduction in any medium, provided the original author(s) and source are credited.

\section{References}

Billet S, Aguilar F, Baudry C, Clauser E (2008) Role of angiotensin II AT(1) receptor activation in cardiovascular diseases. Kidney Int 74(11):1379-1384

Bodor GS, Oakeley AE, Allen PD, Crimmins DL, Ladenson JH, Anderson PA (1997) Troponin I phosphorylation in the normal and failing adult human heart. Circulation 96:1495-1500

Bristow MR, Minobe WA, Raynolds MV, Port JD, Rasmussen R, Ray PE, Feldman AM (1993) Reduced beta 1 receptor messenger RNA abundance in the failing human heart. J Clin Invest 92:2737-2745. doi:10.1172/JCI116891

Bryant D, Becker L, Richardson J, Shelton J, Franco F, Peshock R, Thompson M, Giroir B (1998) Cardiac failure in transgenic mice with myocardial expression of tumor necrosis factor-alpha. Circulation 97:1375-1381

de Tombe PP (2003) Cardiac myofilaments: mechanics and regulation. J Biomech 36:721-730. doi:10.1016/S0021-9290(02) 00450-5

El Armouche A, Pohlmann L, Schlossarek S, Starbatty J, Yeh YH, Nattel S, Dobrev D, Eschenhagen T, Carrier L (2007) Decreased phosphorylation levels of cardiac myosin-binding protein-C in human and experimental heart failure. J Mol Cell Cardiol 43:223-229. doi:10.1016/j.yjmcc.2007.05.003

Francis GS (2001) Pathophysiology of chronic heart failure. Am J Med 110(Suppl 7A):37S-46S. doi:10.1016/S0002-9343(98) 00385-4

Hamdani N, Kooij V, van Dijk S, Merkus D, Paulus WJ, Remedios CD, Duncker DJ, Stienen GJ, van der Velden J (2008) Sarcomeric dysfunction in heart failure. Cardiovasc Res 77: 649-658. doi:10.1093/cvr/cvm079

Jacques AM, Copeland O, Messer AE, Gallon CE, King K, McKenna WJ, Tsang VT, Marston SB (2008) Myosin binding protein C phosphorylation in normal, hypertrophic and failing human heart muscle. J Mol Cell Cardiol 45:209-216. doi:10.1016/j.yjmcc. 2008.05.020

Jin W, Brown AT, Murphy AM (2008) Cardiac myofilaments: from proteome to pathophysiology. Proteomics Clin Appl 2:800-810. doi:10.1002/prca.200780075

Lanfear DE (2008) Genetic variation in the natriuretic peptide system and heart failure. Heart Fail Rev [Epub ahead of print]

LeWinter MM (2005) Functional consequences of sarcomeric protein abnormalities in failing myocardium. Heart Fail Rev 10:249 257. doi:10.1007/s10741-005-5254-4

Lim MS, Sutherland C, Walsh MP (1985) Phosphorylation of bovine cardiac C-protein by protein kinase C. Biochem Biophys Res Commun 132:1187-1195. doi:10.1016/0006-291X(85)91932-1

Mahmoudabady M, Mathieu M, Dewachter L, Hadad I, Ray L, Jespers P, Brimioulle S, Naeije R, McEntee K (2008) Activin-A, transforming growth factor-beta, and myostatin signaling pathway in experimental dilated cardiomyopathy. J Card Fail 14:703-709. doi:10.1016/j.cardfail.2008.05.003

Maron BJ (2004) Hypertrophic cardiomyopathy: an important global disease. Am J Med 116:63-65. doi:10.1016/j.amjmed.2003. 10.012

McDonald KS, Herron TJ (2002) It takes "heart" to win: what makes the heart powerful? News Physiol Sci 17:185-190

Messer AE, Jacques AM, Marston SB (2007) Troponin phosphorylation and regulatory function in human heart muscle: 
dephosphorylation of Ser23/24 on troponin I could account for the contractile defect in end-stage heart failure. J Mol Cell Cardiol 42:247-259. doi:10.1016/j.yjmcc.2006.08.017

Nakao K, Minobe W, Roden R, Bristow MR, Leinwand LA (1997) Myosin heavy chain gene expression in human heart failure. J Clin Invest 100:2362-2370. doi:10.1172/JCI119776

Radauceanu A, Ducki C, Virion JM, Rossignol P, Mallat Z, McMurray J, Van Veldhuisen DJ, Tavazzi L, Mann DL, Capiaumont-Vin J, Li M, Hanriot D, Zannad F (2008) Extracellular matrix turnover and inflammatory markers independently predict functional status and outcome in chronic heart failure. $\mathbf{J}$ Card Fail 14:467-474. doi:10.1016/j.cardfail.2008.02.014

Ram CV (2008) Angiotensin receptor blockers: current status and future prospects. Am J Med 121:656-663. doi:10.1016/ j.amjmed.2008.02.038

Ratnasamy C, Kinnamon DD, Lipshultz SE, Rusconi P (2008) Associations between neurohormonal and inflammatory activation and heart failure in children. Am Heart J 155:527-533

Stelzer JE, Patel JR, Walker JW, Moss RL (2007) Differential roles of cardiac myosin-binding protein $\mathrm{C}$ and cardiac troponin $\mathrm{I}$ in the myofibrillar force responses to protein kinase A phosphorylation. Circ Res 101:503-511. doi:10.1161/CIRCRESAHA.107.153650

Sumandea MP, Burkart EM, Kobayashi T, de Tombe PP, Solaro RJ (2004) Molecular and integrated biology of thin filament protein phosphorylation in heart muscle. Ann NY Acad Sci 1015:39-52. doi:10.1196/annals.1302.004
Torre-Amione G, Kapadia S, Lee J, Durand JB, Bies RD, Young JB, Mann DL (1996) Tumor necrosis factor-alpha and tumor necrosis factor receptors in the failing human heart. Circulation 93:704-711

van der Velden J, Narolska NA, Lamberts RR, Boontje NM, Borbely A, Zaremba R, Bronzwaer JG, Papp Z, Jaquet K, Paulus WJ, Stienen GJ (2006) Functional effects of protein kinase C-mediated myofilament phosphorylation in human myocardium. Cardiovasc Res 69:876-887. doi:10.1016/j.cardiores.2005.11.021

van Empel VP, De Windt LJ (2004) Myocyte hypertrophy and apoptosis: a balancing act. Cardiovasc Res 63:487-499. doi:10.1016/j.cardiores.2004.02.013

Xiao L, Zhao Q, Du Y, Yuan C, Solaro RJ, Buttrick PM (2007) PKCepsilon increases phosphorylation of the cardiac myosin binding protein $\mathrm{C}$ at serine 302 both in vitro and in vivo. Biochemistry 46:7054-7061. doi:10.1021/bi700467k

Yankey GK, Li T, Kilic A, Cheng G, Satpute A, Savai K, Li S, Moainie SL, Prastein D, DeFillipi C, Wu ZJ, Griffith BP (2008) Regional remodeling strain and its association with myocardial apoptosis after myocardial infarction in an ovine model. J Thorac Cardiovasc Surg 135:991-998

Zaremba R, Merkus D, Hamdani N, Lamers JMJ, Paulus WJ, dos Remedios C, Duncker DJ, Stienen GJM, van der Velden J (2007) Quantitative analysis of myofilament protein phosphorylation in small cardiac biopsies. Proteomics Clin Appl 1:1285-1290 